\title{
Parenting Styles and Classroom Social Interaction among Senior High School Students
}

\author{
Norman Mark A. Ramento \\ Quinapondan National High School
}

\begin{abstract}
The purpose of quantitative correlational study was to determine the relationship between demographic profile, the parenting styles, and classroom social interaction of the respondents. This study included 209 senior high school students of Quinapondan National High School. The respondents accomplished the questionnaire pertaining to assess parenting style and classroom social interaction of the respondents. Quantitative data analysis methods were used including mean, frequency count and percentage as well as correlational analysis.

Age has no significant relationship with the parenting styles. It reflects an index of correlation at .137 and p-value .270. Sex also shows no correlation with the parenting styles. It has an index of correlation .068 and p-value .033. Grade level shows no significant relationship with the parenting styles. There is an index of correlation of .027 and p-value of .694. Strand shows no significant relationship with the parenting style. There is an index of correlation of .137 and p-value of .141. Family income has a low correlation with the parenting style but has no significance with the index of correlation of .223 and p-value of .141. Lastly, educational attainment of parents has also a low correlation and has significance with the parenting styles in the index of correlation of .241 and pvalue of .016.

Parenting styles has a significant relationship with the classroom social interaction of the student. There is an index of correlation of .377 and p-value of .000 .

This study suggested that students must encourage themselves to actively participate in class. They must show their full potential to be productive in every activity given to them by the teachers. Teachers must have a close monitoring of the students and must immediately give feedback and share it with parents so that hand in hand, both teachers and parents can make interventions on how to enhance students' classroom participation. Parents must undergo seminars on good parenting. Since they are the source of strength and motivation of the students to perform well in class.
\end{abstract}

Keywords: attachment parenting, child-centered parenting, family income, social interaction, positive parenting.

\section{Introduction}

Children's needs guide from their parents, while they are still young and the actions of the parents that they can see is being imitated. Dewar (2010-2018) states that children are being influence by their parents through the specific practices which includes encouragement and helping them, but parenting is different, it does not focus only on and specific practice but to an overall approach. Parents should guide, control and socialize their children, and thought attitudes. In this pattern that is 
also called as parenting style, the children's will be able to be developed.

Parenting practices are important when it comes to behavioral development of a children. Ensuring children's health and safety, preparing children for life as productive adults, and transmitting culture values is the main goal. It is not easy to become a successful parent; it depends on a variety of environmental and biological factors. There is a complexity which is to organize parenting behavior into four parenting styles the authoritarian, permissive, uninvolved, and authoritative. (Mullins et al., 2018)

As supported by Giuseppe (2019), parents are preparing the children for the future but with the high level of inequality with a high return to the educators, the parents are treated by the chance their child might take the wrong direction of their life or failed to finished studies in school. Parents can choose either they will be relaxed or control their children.

Moreover, millennial and old parents consider themselves that they are different in parenting styles. Millennial parents are protective to their children while generation $\mathrm{x}$ boomer parents, but when it comes to the younger children, they are same overprotective compared to boomer parents. In contrast half of Gen x and boomer parents says they sometimes criticize too much while Gen $\mathrm{x}$ and boomers say they sometimes give too much praise (Doinita and Maria, 2015).

Parenting styles reflect how a parent disciplined and socialize a child, and an attachment is an early biological survival drive between an infant and the primary caregiver (mother). Parental styles, on the other hand, describe the emotional climate created as parent's attempt to socialize their children. Ultimately, it is the interaction of early attachment and parenting styles that influences perceptions about relationships, self-esteem, and self-discipline. In connection with this, raising children brings great joy as you watch them grow, develop and be their own unique person. In most families find that parenting is a journey of ups and downs. Most parents learn parenting on the job and grow into their role with experience. Diana Bannrind's formative research in the 1960s, outlined a three-group classification system; control demandingness, supervision and discipline, lastly responsiveness. Meanwhile, contemporary researchers classify parenting style into four groups: indulgent permissive parenting, authoritative parenting, and neglectful parenting (Borstein et al., 2014).

Parenting style constitutes a concept in parenting research. In particular, the psychological control dimensions have been explicitly modelled and there is limited insight into joint parenting style that characterizes maternal and paternal practices. ANOVA's demonstrated that having authoritative parents associated with the most favorable outcomes, while having authoritarian parents with the least favorable outcomes. Outcomes demonstrated that accounting for parental psychological control did not yield additional parenting styles but enhances our understanding of the pattern among the three-parenting dimension within each parenting style and their association with child. (Sofie K and Eva C., 2019).

\section{Conceptual Framework}

\section{Review of related literature}

\section{Positive Parenting}

When it comes to raising a child, everyone become fathom to the Parents Child Relationship Status. Positive Parenting technique has a good positive outcome to the discipline and moral value of the child. However, it is not as easy as it is. In addition, mishandling the technique outcast its effectiveness. Thus, the misused of the good Parenting Style can affect the child's behaviour of socializing in the society. Moreover, parents need to understand where and when to set boundaries, to encourage and/or to discourage the child. Thus, this set of thinking of the parents abdicate the child to misbehave. Hence, this make them as good parents as well (Dada Bhagwan Foundation, 
2020).

Once you understand the logic behind your child's misbehaviour you can then correct their mistaken belief about how to feel loved, powerful and valued in the world (Godfrey 2019). From the point of view of Godfrey towards positive parenting, parents need to understand not just the characteristics of the child but as well as the behavioural aspect of the child. Thus, this aspect helps them to understand the parent's way of discipline. Furthermore, positive parenting helps to build the child self-esteem and help to build trust and mutual respect that certainly retain a positive influence to the child throughout his teenage years and as well as his adulthood. In relation to this, his behaviour towards his peers or to the society is positive as well. He then, learn to trust someone for a certain thing the way he was taught by his parents to trust.

Parenting for Brain (2020) emphasizes 8 tips on practicing positive discipline namely: first, focus on the reason behind the action. Know the reason behind the childs unethical behaviour because every action of the child behaviour always has a reason. Parents need to understand and hear out gently his reason. Second, kind and firm discipline. Be a role model of respect to others because children learn fast by mimicking the action they see. In relation to this, "when a parent yells, humiliate or calls a child a name, the child learns to do the same when he's upset" (Parenting for Brain 2020). Thus, this bad impact to the child cognitive understanding isolate him from his peers to the society he is currently moving into. Third, time out yourself. It is matter of giving yourself if a space to think of the ways to deal with the issues. Fourth, be non-punitive. Be years by Dr. Nelsen, punitive punishment produces four R's that do not help a child learn-Resentment, Rebellion, Revenge and Retreat (Parenting for Brain 2020)". Do not punish the child by simply isolating him from the outdoors learning. Thus, this might trigger the child to develop into being introvert kind of a person. Fifth, be clear, be consistent, and follow through. You must decide and explain to the child the consequences by violating their limits. If there a inconsistency of the parents, the child will keep on testing their limits. Which this may leads to unethical behaviour of being a rebel to the parent and/or to the society. Sixth, Understand Brain Development and Appropriate Behavior. Parents must understand the Brain Development of the child before imposing correctional measures. Seventh, Make it a Learning Opportunity. Parent must keep in mind that every mistake is a lesson. Help the child to learn and accept the mistakes he done and then correct it for the next chapter of his life. Lastly, be patient and don't despair. Positive discipline most likely wants produce the behavioural change parents want overnight. (Parenting for Brain 2020)." It is not about teaching the child a behaviour to practice over a period of time. Be patient and do not push the child to change fast because it will affect the child behaviour towards his peers.

\section{Statement of the Problem}

This study aimed to determine the relationship between parenting styles and classroom social interaction of the senior high school students in Quinapondan National High School for the school year 2019-2020.

Specifically, it sought answers on the following questions:

1. What is the demographic profile of the respondents in terms of the following:

a. Age,

b. Sex,

c. Grade Level,

d. Strand,

e. Income of Parents, and 
f. Educational Attainment of Parents?

2. What is the status of the respondents in terms of:

$\checkmark$ Parenting style, and

$\checkmark$ Classroom interaction?

3. Is there a significant relationship between the demographic profile of the respondents and parenting styles?

4. Is there a significant relationship between parenting styles and classroom social interaction?

\section{Scope and delimitation}

There is no such absolute study. It will always have boundaries and restrictions. Parameters must be defined, and variables must be clearly identified. This study has the following limitations.

This study engrossed on the relationship between parenting styles such as positive parenting, childcentered parenting and attachment parenting and classroom social interaction of the respondents. The study was conducted in Quinapondan National High School, covering senior high school students for school year 2019-2020.

This study was restricted on the analysis of the relationship between parenting styles such as positive parenting, child-centered parenting and attachment parenting and classroom social interaction of the respondents

The respondents of this study were the senior high school students of Quinapondan National High School for the school year 2019-2020.

The data were collected through some adopted survey questionnaires. Such were enclosed in an envelope to safeguard the identity of the respondents since the study is highly confidential. Explanation regarding the purpose of the study to the respondents were offered as deemed necessary.

\section{Research Methodology}

\section{Research Design}

This study focused the relationship between Parenting Styles and Classroom Social Interaction among senior high school students in Quinapondan National High School for the school year (20192020).

This study used descriptive correlational research design. Descriptive research aims to accurately and systematically describe a population or phenomenon. It answered what, when, where, when, and how question, but not why question. To determined cause and effect, experimental research was required (Shona Mc Combes, 2019). According to (Cresswell, 2008) correlational research designs were used by investigator to describe and measure the degree of relationship between two or more variables or sets of scores.

\section{Population and Sample}

This study was conducted in Quinapondan National High School situated at Barangay 01, Quinapondan, Eastern Samar. This study was delimited to the senior high school students in the said district for the school year 2019-2020.

The participants in this study were the Senior High students of Quinapondan National High School for the school year 2019-2020.

In identifying the population and initiating the sampling, the researcher used the Slovin's formula 
with .05 margin of error. From 437 populations, it was narrowed down to 209 respondents. The total number of respondents was divided into two for the two grade levels.

\section{Instrumentation}

The survey questionnaire comprised of three parts. The first part of the questionnaire focused on the profile of the respondents in terms of their name (optional), age, gender, sex, grade level, strand, family income and educational attainment of parents.

The second part focused on the parenting styles which encompassed positive parenting, childcantered parenting and attachment parenting. The researcher used the 5-point Likert scale, a form of psychometric scale (a scale that measures mental traits, capacities, and processes) in which the respondents answered 44 items indicated by 5-point Liker scale where 1 scaled as never, 2 as rare, 3 as sometimes 4 , often and 5 always.

The last part focused on classroom social interaction of the students, composed of 8 questions and the researcher also used the 5-ponit Likert scale where 1 scaled as never, 2 as rare, 3 as sometimes 4 , often and 5 always.

\section{PRESENTATION, ANALYSIS, AND INTERPRETATION OF DATA}

\section{Summary of Findings}

The treatment of data reveals the following essential findings.

Most of the respondents are 17 years old with 17 or 36.2 percent which was interpreted as the highest frequency and percentage. This study was dominated by the females 130 or 61.9 percent and reflected as the highest frequency or percentage. Respondents were also dominated by ICT and ABM students with 70 or 33.5 percent which both considered as the highest frequency or percentage. Majority of the respondents were from grade 11 with 107 or 51.2 percent which is also reflected as highest frequency and percentage. For family income, majority of the parents of the respondents were in the bracket of 5-10 thousand with 181 or 86.6 percent which was reflected as the highest frequency and percentage. Lastly, most of the parents were high school level of educational attainment with 119 or 56.9 percent and was also interpreted as the highest frequency and percentage.

Majority of the respondent's parents were good in parenting and were able to encourage their children to perform well especially in classroom social interaction. Based on the result, in terms of parenting styles frequency of 104 or $49.5 \%$ were recorded and interpreted as admirable. Also, majority of the respondents were desirable when it comes to classroom social interaction with 98 frequency or 46.7 percent.

Age has no significant relationship with the parenting styles. It reflects an index of correlation at .137 and p-value .270. Sex also shows no correlation with the parenting styles. It has an index of correlation .068 and p-value .033. Grade level shows no significant relationship with the parenting styles. There is an index of correlation of .027 and p-value of .694. Strand has no significant relationship with the parenting styles. It reflects an index of correlation at .137 and p-value .141. Family income has a low correlation with the parenting style but has no significance with it showing the index of correlation of .223 and p-value of .141.

However, educational attainment of parents has also a low correlation and has significance with the parenting styles showing an index of correlation of .241 and p-value of .016 . The result rejects the null hypothesis stating that there is no significant relationship between demographic profile and parenting styles. This goes to show that the educational attainment of the parents has significant bearing on the parenting practices observed at home by the parents. This is alike to the study by 
Michelle Elizabeth George, 2004 stated that the parent's educational attainment could affect parents in choosing their parenting styles. The higher the educational attainment of parents the parenting style was somehow good and have positive impact to the social behavior of the child.

Lastly, parenting styles has a significant relationship with the classroom social interaction of the students. There is an index of correlation of .377 and p-value of .000 . Comparable to the study of Banerjee and Khanna, 2018 stated that social skills of children depend on the family environment. According to the study the social integration, interaction and presentation skills of children are nurtured by the family values and home ambiance. It was mentioned that the parents need to improve in creating social positive skills of children.

\section{Conclusions}

Based on the findings, the following conclusions are drawn.

Based on the findings revealed, the following conclusions were drawn. Majority of the respondents were 17 years old with 17 or 36.2 percent. This study was dominated by the females 130 or 61.9 percent. Respondents were also dominated by ICT and ABM students with 70 or 33.5 percent. Majority of the respondents were from grade 11 with 107 or 51.2 percent. For family income, majority of the parents of the respondents were in the bracket of 5-10 thousand with 181 or 86.6 percent. Finally, most of the parents were high school level of educational attainment with 119 or 56.9 percent.

Majority of the parents of the respondents were good in terms of parenting with 104 frequency or 49.5 percent who were rated as admirable. Also, majority of the respondents were desirable when it comes to classroom social interaction with 98 frequency or 46.7 percent.

Parenting styles has a significant relationship with the classroom social interaction of the student. There is an index of correlation of .377 and p-value of .000. Thus, a good parenting style can help a student to perform well in class.

\section{Recommendations}

In the light of the foregoing conclusions, the following recommendations are hereby offered:

1. Students must encourage themselves to actively participate in class. They must show their full potential to be productive in every activity given to them by the teachers because according to Clarke 2020, every child has developmental stages that transformed him/her into new and broader way of himself. These changes may affect the way he/she thinks, feel and interact with others. Thus, the child develops his/her unique personality and opinions.

2. Teachers must have a close monitoring of the students and must immediately give feedback and share it with parents so that hand in hand, both teachers and parents can make interventions on how to enhance students' classroom social interaction.

3. Parents and teachers must undergo seminars on good parenting. Since, they are the source of strength and motivation of the students to perform well in class.

4. The Department of Education specially Division of Eastern Samar should be the one who will initiate these seminars and should be religiously done in every school year. Having enough information about parenting practices would surely help the students in their academic performance.

5. In this study it was also recommended that, in the curriculum subjects related to parenting styles and classroom social interaction of the students should be taught in school because according to Shoage, Opeye $\mathrm{PhD}, 2015$ educators should ensure to give effective parenting practices to the 
students in order to give students a good social interaction in the school.

\section{Policy Note}

\section{PARENTING STYLES AND CLASSROOM SOCIAL INTERACTION AMONG SENIOR HIGH SCHOOL STUDENTS}

NOTE: This study was conducted to investigate the parenting styles and classroom social interaction of the senior high school students in Quinapondan National High School, school year 2019-2020.

\section{References}

1. Barbara M. Parent Development theory: Understanding Parents, Parenting. Perceptions and Parenting Behaviors. Journal of Early Childhood and Infant Psychology. Academic Journal Article.

2. Bornstein L. and Bornstein M. (2014). Parenting Styles and Child Social Development. University of Pennsylvania, USA. National Institute of Child Health and Human Development, USA. Retrieved from http://www.child-encyclopedia.com/parenting-skills/accordingexperts/parenting-styles-and-child-social-development

3. Clarke K. (2020). Developmental Milestones. Centers for Disease Control and Prevention Retrieved from positiveparenting/adolescenc $2 . \mathrm{html}$

https://www.cdc.gov/ncbddd/childdevelopment/

4. Fuentes M. et al.(n.d). Effects of Parenting Styles on Self-Regulated Learning and Academic Stress in Spanish Adolescent. Retrieved from https:// www.ncbi.nlm.nih.gov/pmc/articles/PMC6696365/

5. Hosokawa R. and Katsura T. (2019). Role of Parenting Style in Children's Behavioral Problems through the Transition from Preschool to Elementary School According to Gender in Japan. Retrieved from https:// www.ncbi.nlm.nih.gov/pmc/articles/PMC6339084/

6. Kuppens S. and Ceulemans E. (2019). Parenting Styles: A Closer Look at a Well-known Concept. J Child Fam Stud. Retrieved from https://www. ncbi.nlm.nih .gov/pmc/articles/PMC6323136/

7. Latouf N. and Dunn M. (2020). Parenting Styles Affecting the Social Behaviour of Five-Years Olds. Informa UK Limited Retrieved from https://www.tandfononline.com/doi/abs/10.1080/14330237.2010.10820350

8. Lawson C. (2003). Social Skills and School. Retrieved from https://www.cdl.org/aticles/socialskills-and-school/

9. Londen A. \& Stevens L. (2019). Teaching and Parenting Styles Related to Children's Achievement Motivation and Learning Outcomes. Retrieved from Trends and prospects in Motivational Research

10. Sorrenti G. (2019). What kind of parent are you?. Learning Environment. Retrieved from https://www.psychologyinaction.org/psychology-in-action-1/2018/4/23

17ziyfqt1vy9tlytr919k48epdnur

11. South Australia (2020). Parenting Style- Parent Easy Guide. South Australia Department of Education. Retrieved from https://www. education.sa. gov.au/parenting-and-childcare/parenting/parenting-sa/parent-easy-guides/parenting-style-parent-easy-guide

12. Thompson P. S. (2017). Attachment, parenting, and childhood adversity. ScienceDirect and trademark

of Elsevier

B.V.

Retrieved

from 
https://www.sciencedirect.com/topics/psychology/parenting-style

13. Tu Y.C \& Chou M.J. (2013). Interrelationships between Parenting Styles and Teachers Involvement: From Children's Emotion Regulation Competence Perspective. Retrieved from Children's Emotion Regulations Competence Perspective. Journal of Applied Sciences.

14. Tu Y.C \& Chou M.J. (2013). Interrelationships between Parenting Styles and Teachers Involvement: From Children's Emotion Regulation Competence Perspective. Retrieved from Children's Emotion Regulations Competence Perspective. Journal of Applied Sciences.

15. Zahedani Z. et al.(2016). The influence of parenting style on academic achievement and career path. Retrieved from https://www.ncbi.nlm.nih.gov/pmc/articles/PMC4727255/

16. Fuentes M. et al.(n.d). Effects of Parenting Styles on Self-Regulated Learning and Academic Stress in Spanish Adolescent. from https://www.ncbi.nlm.nih.gov/pmc/articles/PMC6696365/

17. Essays, U.K. (2013). Parenting Style And Children's Classroom Performance Education Essay. Retrieved from https://www.uniassignment.com/essay-samples/education/parenting-styles-andchildrens-classroom-performance=education-essay.php?vref $=1$

18. Joseph M.V \& John J. (2008). Impact of parenting styles on child development. Retrieved from http://scholararticles.net/impact-of-parenting-etyles-on-child-development/ 